\title{
The Comparison of Job Stress among Dental Professionals of Dentistry Faculty Members of Tabriz University
}

\author{
Seyyed Vahid Dehnad', Mohammad Ali Ghavimi2 ${ }^{*}$, Arezu Ghoreishizadeh ${ }^{3}$, Parisa Falsefi ${ }^{4}$, \\ Ramin Negahdari ${ }^{5}$ and Amir Reza Babalou ${ }^{6}$ \\ ${ }^{1}$ Resident of Oral and Maxillofacial Surgery, Tabriz University of Medical Sciences, Tabriz, Iran \\ 2Department of Oral and Maxillofacial Surgery, Tabriz University of Medical Sciences, Tabriz, Iran; \\ m_ghavimi@yahoo.com \\ ${ }^{3}$ Department of Pediatric Dentistry, Tabriz University of Medical Sciences, Tabriz, Iran \\ ${ }^{4}$ Department of Oral Medicine, Tabriz University of Medical Sciences, Tabriz, Iran \\ ${ }^{5}$ Department of Prosthodontics, Tabriz University of Medical Sciences, Tabriz, Iran \\ ${ }^{6}$ Department of Priodontology, Tabriz University of Medical Sciences, Tabriz, Iran
}

\begin{abstract}
Several studies have so far focused on occupational stress among dentists and the results have shown that many factors can cause stress. However, the level of stress among experts in the fields of dentistry has not yet been studied in Iran. The aim of this study is to examine the causes and levels of job stress among dental professionals in Tabriz University of Medical Sciences. This cross-sectional study included all dental professionals of Dentistry Faculty; an overall of 55 subjects in Tabriz were studied in this research and their level of stress was evaluated using "The Health and Safety Executive Management Standards Indicator Tool" (HSE stress questionnaire) from September up to October 2014. The level of stress in each dental specialty was examined descriptively (mean, standard deviation). Statistical analysis was performed using SPSS 20. The findings of the study showed that the highest stress among dental professionals from different fields was observed in the field of oral and maxillofacial radiology; fields of oral medicine, endodontics, oral and maxillofacial surgery and pediatric dentistry ranked later. The lowest stress was seen among orthodontics specialists. Based on the results of the present study, the rate of job stress varied significantly among dental professionals.
\end{abstract}

Keywords: Burnout, Dental, Education, Professional, Stress

\section{Introduction}

Stress is a reaction to compromise with factors or circumstances that put individuals under physical or mental pressure ${ }^{1}$. In the 1930s, a new concept of stress was presented which included anything unpleasant, harmful, or excessively exhausting ${ }^{2,3}$. Some experts believe that stress at work is the result of high demand and low control of the situation ${ }^{4}$. The importance of job stress is second only to the stresses in the family ${ }^{5}$. Factors of individuals' jobs due to interference in the lifestyle, social status, and income, work environment, and it is stressful nature can cause psychological pressure that can lead to behavioral, psychological, and social disorders ${ }^{6}$. Dentistry is commonly known as a stressful profession among various occupations. The general level of stress depends on the patient-dentist relationship and job satisfaction, the high demands of work, exposure to toxic substances, and long working hours as the most important reasons underlying job stress among dentists ${ }^{7}$. Stress often roots in the demanding nature of clinical work, job environment, and the personality of those who have chosen the profession of focusing on small areas of the oral cavity. Various types and degrees of job stress with which dentists facing are mainly related to time, job, income, technical issues, and patients ${ }^{8}$. In a study involving 484 dentists, stressors related

${ }^{*}$ Author for correspondence 
to time and patients were identified as the most important factors 9 . In another study, stress levels among dentists working in surgery and dentists in dental care centers were compared and there was a statistically significant difference between the two groups, although the identified stress sources were different due to differences in the workplaces ${ }^{10}$. Henry presented the association of stress and coronary heart disease among American dentists ${ }^{11}$. Wilson et al., also, introduced time management as the highest source of stress among dentists ${ }^{12}$. The Swedish Dental Association claims that dentists live an average of 10 years less than the total population of the country because of some occupational hazards, such as exposure to psychological stress, emotional exhaustion, tension, sadness, and anxiety ${ }^{13}$. Another study presented common stressors among dentists in New Zealand, including the treatment of children as patients (52\%), time pressure (48\%), and difficulty in concentration (42\%). Suggested strategies for coping with stress included interaction with people, exercise, and easing about job problems ${ }^{14}$. Dental students are more stressed than students studying in other fields of medical sciences ${ }^{15}$. Cameiro et al. concluded that the majority of oral-maxillofacial surgeons, exercise their profession in unsatisfactory working conditions, as less than $1 / 3$ of the population studied worked under the ideal condition of low demand ${ }^{16}$. Chingarande et al. revealed that there was a high incidence of occupational stress among medical radiographers working in general radiology. The results also showed that the most frequently encountered stressors in the general radiology department were pressure to complete tasks, overwork, inadequate salaries, and inadequate holiday or vacation time ${ }^{17}$. A mental health study of 317 medical and dental students in Saudi Arabia concluded that the level of stress and anxiety was different among students in different academic years; stress and anxiety increased when students progressed to upper semester. Female students were stressed more than male students, and dental students were more stressed students of other fields of medical sciences ${ }^{18}$. Dental students experience a significant amount of stress during their training (due to the nature of dental education). In addition, the adverse effects of stress can be shown to dental students' health as well ${ }^{19}$.

Given the importance of the issue and considering the fact that job stress can have very negative impacts on job performance and job satisfaction and it can cause physical and psychological conditions and diseases among the working people, and taking into consideration the fact that no comprehensive study on job stress among dental professionals has been done in this country ${ }^{22,23}$, the present researchers decided to conduct a study to examine the variety and intensity of job stress among dental professionals in Tabriz.

\section{Materials and Methods}

\subsection{Statistical Population of the Study}

The statistical population of this cross-sectional study included dental specialists who were faculty members at Tabriz University of Medical Sciences. The sample size included all dental specialists of Tabriz University of Medical Sciences, an overall of 55 subjects. The amount of stress was measured through the Job Stress Questionnaire (HSE), including 35 questions with a fiveoption Likert scale (never, rarely, sometimes, often, or always) completed by dental specialists. The validity and reliability of the Farsi version of the questionnaire were previously studied by Azadmarzabadi et al. ${ }^{20}$; however, the content validity of the questionnaire was assessed by four professors and the required changes were made. In order to study the reliability, a pilot study was performed among twenty cases and Cronbach's alpha was estimated as 0.79 .

The individual score of each item represented a measured value, ranging from 1 to 5 , where 1 is the least desirable and 5 is the most desirable possible. Items 3,5 , $6,9,12,14,16,18,20,21,22$, and 34 were scored reversely.

The minimum score achieved on the questionnaire was 35 , while the maximum was 175 . Respondents with scores over 105 were considered to have higher than average stress. For implementation, we explained the general plan to all eligible individuals and after that participant was asked to complete questionnaires to assess job stress. Once the questionnaires were completed, they were collected. Incomplete questionnaires were excluded. SPSS 20 was, then, used for data analysis. The Kruskal-Wallis test was used to compare averages among different groups. A $\mathrm{P}$-value of less than 0.05 was considered significant in the comparison of the averages among different groups.

\subsection{Ethical Considerations}

The ethical authenticity of the study was assessed and approved by the Ethics Committee of Tabriz University 
of Medical sciences and required written consent was taken; a necessary fund to conduct the present study was provided by the authors.

\subsection{Statistical Population of the Study}

This study included 55 subjects active in ten different fields of Dentistry. Table1 shows the frequency of each field separately.

Table 1. The frequency of professionals in each field of dentistry

\begin{tabular}{lcc}
\hline Item & Number & Percentage \\
\hline Oral and maxillofacial radiology & 4 & 7.27 \\
Oral medicine & 5 & 9.09 \\
Prosthesis & 11 & 20.00 \\
Oral and maxillofacial pathology & 4 & 7.27 \\
Endodontics & 3 & 5.45 \\
Periodontics & 6 & 10.91 \\
Orthodontics & 8 & 14.55 \\
Oral and maxillofacial surgery & 4 & 7.27 \\
Restorative dentistry & 5 & 9.09 \\
Pediatric dentistry & 5 & 9.09 \\
\hline Total & $\mathbf{5 5}$ & $\mathbf{1 0 0 . 0}$ \\
\hline
\end{tabular}

Table 2. Average, standard deviation, and minimummaximum levels of job stress among dental professionals

\begin{tabular}{|l|c|c|c|c|c|}
\hline & Number & $\begin{array}{c}\text { Mini- } \\
\text { mum }\end{array}$ & $\begin{array}{c}\text { Maxi- } \\
\text { mum }\end{array}$ & $\begin{array}{c}\text { Aver- } \\
\text { age }\end{array}$ & $\begin{array}{c}\text { Standard } \\
\text { deviation }\end{array}$ \\
\hline $\begin{array}{l}\text { Job } \\
\text { stress }\end{array}$ & 55 & 74.00 & 151.00 & 117.62 & 15.30 \\
\hline
\end{tabular}

The average of job stress in 55 dentistry specialists was 117, ranging from 74 up to 151 variables (Table 2). It should be noted that a maximum score achieved in HSE questionnaire of job stress is 175 and a score of more than 105 (average) means higher than average level of stress.

As the Kruskal-Wallis test ranking showed, the oral and maxillofacial radiology field, with a score of $88 / 44$, ranked highest in terms of stress, followed by oral medicine, endodontics, oral and maxillofacial surgery, and pediatric dentistry, which ranked 33.9, 34.83, 31.5 and 30.9 in order. Prosthesis, pathology, periodontics, and restorative were ranked at the third level, at 29.58, 26.75, and 25.9, respectively, and orthodontics ranked last in terms of job stress [needs mean] (Figure 1).



Figure 1. Average job stress among study participants in terms of specialty.

\section{Discussion}

The Swedish Dental Association claims that, due to occupational hazards, dentists live 10 years less than the total population of the country on average because they are subjected to psychological factors such as stress,

Table 3. Comparison of job stress among dental professionals based on their field

\begin{tabular}{|c|c|c|c|c|c|c|}
\hline \multirow[t]{2}{*}{ Item } & \multirow[t]{2}{*}{ Number } & \multirow[t]{2}{*}{ Average } & \multirow{2}{*}{$\begin{array}{l}\text { Standard } \\
\text { deviation }\end{array}$} & \multicolumn{3}{|l|}{ Kruskal- Wallis Test } \\
\hline & & & & Rank & Chi-Square & P-value \\
\hline Oral and maxillofacial radiology & 4 & 130.75 & 7.41 & 44.88 & & \\
\hline Oral medicine & 5 & 122.4 & 7.7 & 33.9 & & \\
\hline Endodontics & 3 & 122.33 & 2.08 & 34.83 & & \\
\hline Pediatric dentistry & 5 & 121.8 & 12.62 & 30.9 & 17.492 & 0.042 \\
\hline Oral and maxillofacial surgery & 4 & 121 & 9.17 & 31.5 & & \\
\hline Periodontics & 6 & 119.5 & 7.5 & 29 & & \\
\hline Restorative dentistry & 5 & 118.4 & 14.5 & 25.9 & & \\
\hline Prosthesis & 11 & 117.83 & 21.3 & 29.58 & & \\
\hline Oral and maxillofacial Pathology & 4 & 114.25 & 20.84 & 26.75 & & \\
\hline Orthodontics & 8 & 101.88 & 11.76 & 9 & & \\
\hline
\end{tabular}


emotional exhaustion, tension, sadness, and anxiety ${ }^{13}$. The results showed that the mean stress among studied dental professionals in Tabriz was 117.62, which was higher than average. Dental specialists' job stress was higher than average across all fields except orthodontics. The results were compatible with the findings of a study conducted by Rusli et al. ${ }^{7}$ The researchers stated that the specialists' high stress was due to long working hours. The results of the study conducted by Makames et al. ${ }^{8}$ were also consistent with findings of this study; the researchers showed that the lack of time enhances clinical skills as the reason for high stress among dentists. Myers ${ }^{12}$ and Wilson et al. ${ }^{1}$ also introduced time management as the most prominent stressor among dentists. Elani et al. cited that the nature of the work is the major source of stress among dentists ${ }^{19}$. Birks et al. stated that dental students' stress was higher than the level of stress among students of other fields of Medical Sciences ${ }^{15}$. All these studies showed high rate and level of stress among dental specialists, which is consistent with the results of this study. In this study, oral radiology specialists had the highest stress (130.75), compared to other specialists. Such a result is reasonable considering the nature of the field and the risks resulting from X-rays. Chingarande and Ndlovu also declared high job stress among medical radiologists and showed that job stress among female radiographers was significantly higher than that of male radiographers ${ }^{17}$. The results showed that, after oral radiology, specialists in the fields of oral medicine (122.4), endodontics (122.33), oral and maxillofacial surgery (121) and pediatric dentistry (121.8) had the highest stress among the fields studied. In addition, the stress level in the fields of prosthetics (117.83), pathology (114.25), periodontics (119.5), and rehabilitation (118) were ranked the third (in terms of job stress ranking among dental professionals in Tabriz), while the lowest level of job stress was related to orthodontic specialists (101.88). Ayera et al. also introduced the treatment of children as a common stressor among dentists. Child patients are often panicked and resistant to dental treatment; so that it is understandable that endodontic specialists experience more stress during root canal therapy of children. All results related to the field of endodontics, oral and maxillofacial surgery, and pediatric dentistry are compatible with the results of the present study ${ }^{14}$. In this study, periodontics, prosthesis and pathology specialists were ranked third in terms of job stress. Stress was lowest among orthodontic specialists. In a study carried out by Newton et al., pediatric, endodontic, and prosthesis specialists had the highest levels of stress, which is consistent with the results of the present study in terms of stress among pediatric and root canal therapy specialists. However, stress among prosthesis specialists is in contrast to the results of our study; additionally, a dentures specialty was introduced as one of the three most stressful fields, which is inconsistent with results of this study ${ }^{21}$. These differences may be due to age, gender, or work experience of the respondent specialists. Stress is a psychological problem related to gender. According to Radillo et al. ${ }^{5}$, stress is higher among female dentists in comparison to male dentists ${ }^{5}$. In Aboalshamat et al. study, female students had higher stress levels than male students as well ${ }^{18}$. Russek stated that the number of heart complaints in the fields of Periodontology and Orthodontics was higher than in other fields, as much as three times higher in periodontics specialists than in other professionals. The results of that study were inconsistent with results of this study ${ }^{11}$. As mentioned previously, the differences between the results of this study with the other conducted studies may be due to some factors such as gender, age, and work experience, which were not homogenized in the study specialized groups. Therefore, the homogenization of samples is essential in terms of gender, age, and work experience in studying stress among dental specialists. However, lack of control for confounding factors in the present study was due to the unavailability of the professionals, as well as a lack of cooperation from them side; further studies are required in order tom provide more authentic findings and cover more expanded related areas.

\section{Conclusions}

The results of this study showed that the highest stress among dental specialists in different fields of dental specialties was in the field of Oral and Maxillofacial Radiology, followed by the fields of Oral Medicine, Endodontic, Oral and Maxillofacial Surgery and Pediatric Dentistry. The lowest job stress was seen in Orthodontics professionals.

It is recommended that the amount of stress be examined in terms of gender, work experience, and age of specialists in different dental fields for more accurate results. It is also recommended that the amount of stress be examined separately according to sundry patients (e.g., trauma). 
Considering high stress in professionals, the use of stress management strategies in educational programs through workshops seems necessary. To improve the living standards of dentists, it is recommended that the study be done as mandated by the health care system.

\section{Acknowledgement}

Deepest gratitude goes to all professors of Dentistry School of Tabriz University of Medical Sciences and all the stuff cooperating in the present research.

\section{Competing Interest}

The authors declare that they have no conflict of interest.

\section{References}

1. Wilson RF, Coward PY, Capewell J, Laidler TL, Rigby AC, Shaw TJ. Perceived sources of occupational stress in general dental practitioners. Br Dent J. 2008; 184:499-502.

2. Roth S, Heo J, Varnhagen C, Glover K, Major P. Occupational stress among Canadian orthodontists. Angle Orthod. 2003; 73(1):43-50.

3. Radillo B, Lopez T, Velasco M, Pezes G. Stress associated factors in Mexican dentist. Brazo Oral Res J. 2008; 22(3):223-8

4. Arandelovia M, Llia I. Stress in workplace-possible prevention. Medicine and Biology. 2006; 13(3):139-44.

5. Radillo BEP, López TMT, Velasco MLA, Fernández MA, Perez GJG. Stress-associated factors in Mexican dentists. Braz Oral Res. 2008; 22(3):223-8.

6. Moore R, Brodsgaard I. Dentists' perceived stress and its relation to perceptions about anxious patients. Community Dent Oral Epidemiol. 2001; 29(1):73-80.

7. Rusli BN, Edimansyah BA. Prevalence and associated factors of stress in dental healthcare workers of a higher institution of learning in Kelantan. Arch Orofac Sci. 2006; 1:51-6.

8. Makames RA, Alkoot EM, Almazidi BM, Elshazly MK, Kamel ML. Sources and expressions of stress among physicians in a general hospital. Alex J Med. 2012; 48:361-66.

9. Cooper CL, Watts J, Kelly M. Job satisfaction, mental health and job stressors among general dental practitioners in the UK. Br Dent J. 1987; 162:77-81.
10. Humphris G, Peacock L. Occupational stress and job satisfaction in the community dental service of North Wales: A pilot study. Community Dent Health. 1992; 10:73-82.

11. Russek H. Emotional stress and coronary heart disease in American physicians, dentists and lawyers. Am J Med Sci. 2000; 243:716-25.

12. Myers HL, Myers LB. It's difficult being a dentist: stress and health in the general dental practitioner. Br Dent J. 2004; 197(2):89-93.

13. Kamin V. Fear, stress and the well dental office. Northwest Dent. 2006 Mar-Apr; 85(2):10-1,13,15-8.

14. Ayera KM, Thomson WM, Newton JT, Rich AM. Job stressors of New Zealand dentist and their coping strategies. Occup Med (Lond). 2008 Jun; 58(4):275-81.

15. Birks Y, McKendree J, Watt I. Emotional intelligence and perceived stress in healthcare students: a multi-institutional, multi-professional survey. BMC Medical Education. 2009; 9(1):61.

16. Carneiro SCA, Vasconcelos BC, Nascimento MMM, Leal JLF, Orestes MS, Porto GG. Occupational stress among Brazilian oral-maxillofacial surgeons. Med Oral Patol Oral Cir Bucal. 2009 Dec 1; 14 (12):e646-9.

17. George RC, Bekezela N. The prevalence and antecedents of occupational stress among radiographers in Zimbabwe: Interplay of economics and culture. Int J Med Res Health Sci. 2013; 2(2):233-8.

18. Aboalshamat KH, Hou X-Y, Strodl E. Psychological health of medical and dental students in Saudi Arabia: A longitudinal study. Public Health Research. 2014; 4(5):179-84. DOI: $10.5923 / \mathrm{j} . \mathrm{phr} .20140405 .05$.

19. Elani HW, Allison PJ, Kumar RA, Mancini L, Lambrou A, Bedos C. A systematic review of stress in dental students. J Dent Educ. 2014 Feb; 78(2):226-42.

20. Marzabadi A, Gholami F. Reliability and validity assessment for the HSE job stress questionarie. J Behav Scien. 2011 Win; 4(4):291-7.

21. Newton JT, Mistry K, Patel A, Patel P, Perkins MM, Saeed K , Smit C. Stress in dental specialists: A comparison of six clinical dental specialtie. Primary Dental Care. 2002; 9(3):100-4.

22. Abedi GH, Rostami F. Regression model analysis of service desirability in a group of Mazandaran hospitals. Health MED. 2012; 6(1):24-8.

23. Abedi GH, Shojaii J, Rostami F. Analytical approaches of impellent and preventive power on hospital services. World Applied Sciences Journal. 2011; 12(11):2071-7. 